\title{
Influence of the undercut height on the behaviour of pillars at the extraction level in block and panel caving operations
}

\author{
E Hormazabal SRK Consulting (Chile) S.A., Chile \\ R Alvarez SRK Consulting (Chile) S.A., Chile \\ A Russo SRK Consulting (Chile) S.A., Chile \\ D Acevedo SRK Consulting (Chile) S.A., Chile
}

\begin{abstract}
Definition of the undercutting geometry and size is an essential aspect of the design of a block and panel caving operation. Both geometry and size need to be properly established to guarantee the initiation and the development of sustainable propagation of the caving process in a rock mass. Although the required extent of the undercut in the horizontal directions needed for caving management and to avoid damage to pillars has been studied in some detail, the required height of the flat undercut has not received similar attention. Few existing studies suggest that the smaller the height of the undercut, the higher the stress concentrations and, therefore, the higher the magnitude of stresses at the front or abutment of the undercut. These stress concentrations, in turn, can produce negative effects, such as damage in pillars and drifts at both the undercut level (UCL) and extraction level (EXL). This paper investigates the effect of the undercut height on the mechanical response of the rock mass and mine openings in a block caving operation. With this purpose, the problem is simulated using a three-dimensional mechanical model that considers undercut heights of 5,10 , 20 and $40 \mathrm{~m}$ in a typical block/panel caving operation. The model comprises the extraction level, the undercutting level and the broken material surfaces that simulate the undercutting advance. Simulation of the mining process allows one to see the effect that the assumed heights of undercut have on the stress concentrations and plastic damage in pillars at the vicinity of the caving front. Results of the numerical models are correlated with observations of pillar damage in caving layouts used at some mines in Chile.
\end{abstract}

Keywords: block/panel caving mining, undercut height, numerical modelling

\section{$1 \quad$ Introduction}

Caving mines in Chile started as conventional block caving operations hosted in secondary ore. This type of ore corresponds to rock masses that are of poor geotechnical quality, i.e. they are highly fractured rock masses, but are relatively easy to cave. In secondary ore, the caving was induced by flat undercuts with heights usually ranging between 6 and $10 \mathrm{~m}$. The first operations in primary ore, i.e. in rock masses of good geotechnical quality and therefore of low caveability, started during the 1980 s. The increment of stresses at the abutment of the undercuts (due to the use of the same mining layout as for secondary ore) affected the integrity of pillars at the extraction level. This led to a change in the mining method from the original block caving, to conventional panel caving, and later on, to advanced panel caving and then pre-undercut. In the first case, only the production drifts are developed ahead of the caving front, while drawpoint drifts and drawbells are developed behind the caving front. With the pre-undercut method, the entire extraction level is developed behind the caving front. When the method of caving was changed, different flat undercut heights were used as well, ranging from 3.6 up to $17 \mathrm{~m}$; the change in undercut heights targeted to have better results in terms of fragmentation, time and costs of preparation and productivity.

In general, in panel and advanced panel caving, mining started with a higher undercut to ensure caving propagation and productivity. Once mining operations matured and more experience and knowledge was gained on the behaviour of primary ore involved in the caving process, the method changed to a pre-undercut 
caving, which involved developing the extraction level behind the abutment stress zone, using a height of undercut of $3.6 \mathrm{~m}$, with the objective of avoiding stress damages and/or collapses in the extraction level. When using this type of caving configuration, remnant pillars sometimes occurred, leading to localised loading of the rock mass below the undercutting level into the extraction level (Figure 1). Remnant pillars are generated by a concentration of stresses that produce damage in pillars ahead of the caving front at the undercut level. This concentration of stresses at the front damages the blasting holes and results in poor blasting, which in turn generates the large block.

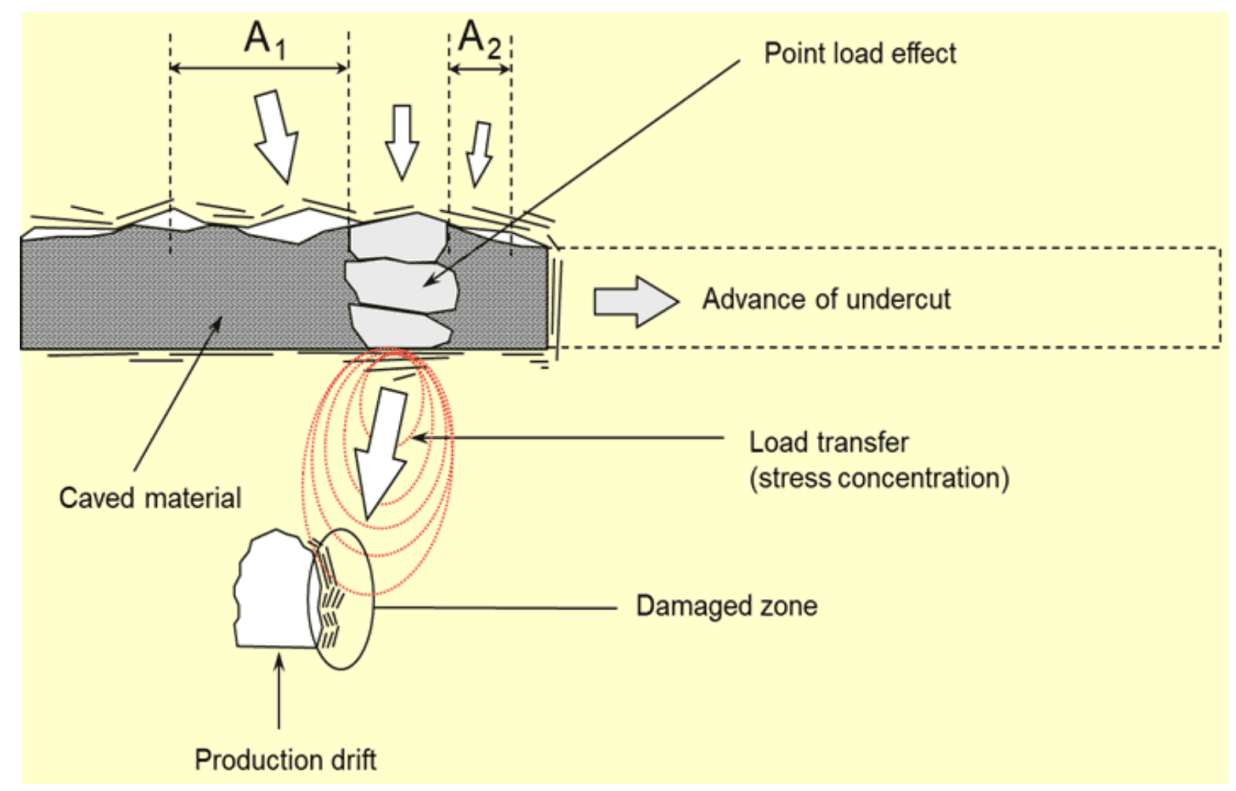

Figure 1 Localised loading at the rock mass below the undercutting level due to coarse fragmentation or due to the occurrence of large block falls in a flat undercut of relatively small height (modified from Karzulovic 1996)

Due to the aforementioned problems, the pre-undercut method, and particularly the flat undercut height, were questioned. As a result, caving operations moved back again to the use of conventional caving with higher flat undercuts. This avoided the generation of remnant pillars and lowered the concentration of stresses at abutments, increasing the stability of pillars. Figure 2 shows the typical conventional (post) undercutting mining sequence.

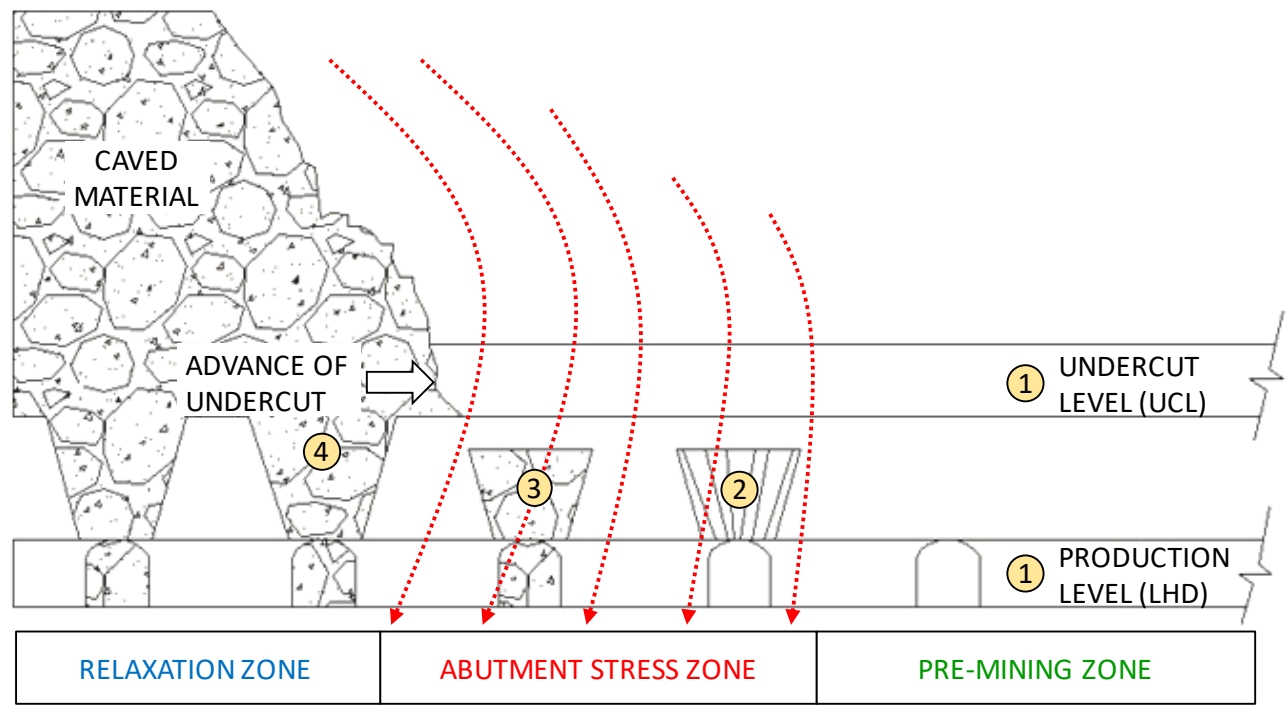

Figure 2 Schematic mining sequence of conventional (post) undercutting 


\section{The undercut height}

A review of the technical literature shows that when caving methods were first introduced, little attention was paid to the undercut height. Recommendations for good caving practices were almost exclusively focused on the required open undercut area (e.g. this is discussed in the technical literature prior to the 1970s), or on the plan perimeter-to-area ratio (the hydraulic radius) of the undercut area (e.g. this is discussed in the technical literature after the 1970s). The reason for ignoring the undercut height can be attributed to the fact that since the early 1980s, all mines using caving methods (mainly block caving) were mining secondary ore (in this case, caving spreads easily, independently of the undercut height).

In a benchmark study, Flores and Karzulovic (2002) observed that undercut heights used in mines for block and panel caving did not change significantly through decades of application of caving methods. This is shown in the histograms in Figure 3, where undercut heights fall in the broad range from 3 to $20 \mathrm{~m}$, with the most frequent values of height being close to $8 \mathrm{~m}$.

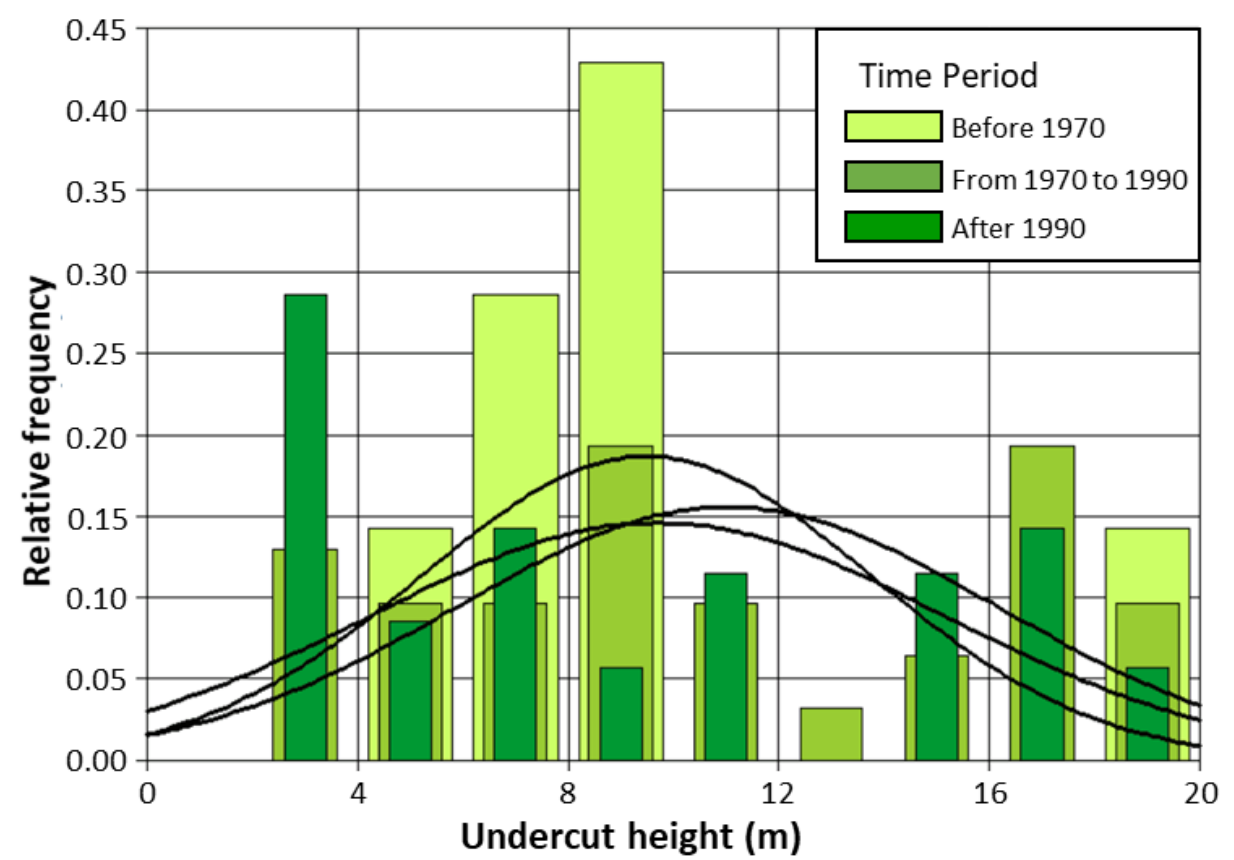

Figure 3 Use of various undercutting heights in block/panel caving operations in recent decades (Flores \& Karzulovic 2002)

More recent studies have indicated that among others, the undercut height influences the spread of caving in the vertical direction; this is in addition to the influence that the undercut height has on the magnitudes of stresses that localise at the abutments (or at the undercutting front), and that also affect pillars at the undercutting level.

For example, McNearny and Abel (1993) studied caving by means of large two-dimensional physical models, obtaining results that indicate that undercut heights affect the vertical caving spread and the gravitational flow (Figure 4). Dai et al. (1996) analysed rock mass failure with a plastic model based on the Cosserat method, obtaining results that indicate that the rock volume affected by the undercut depends on the size of the undercut in relation to the size of the blocks forming the rock mass, and on the block geometry (defined by the ratio between major and minor dimensions of the block, for the case of two dimensions). Shen and Barton (1997) used the distinct element software UDEC to evaluate failure and movement of blocks in a jointed mass around underground openings in two dimensions; their results suggest that in the case of jointed rock, the extent and shape of the failure zone around excavations is linked to the relative size of the opening in relation to the size of the blocks forming the rock mass. Karzulovic et al. (2005) studied the effects of the undercut geometry on undercut level pillars at a sector of the El Teniente mine in Chile, and observed that the undercut height influences the concentration of abutment stresses, also affecting the damage in 
pillars. They also observed that a low value of undercut height in a panel caving scheme that uses preundercut may produce important stress concentrations, as shown in Figure 5 (the authors referred to this concentration of stresses as the 'crack effect').

To summarise, the caving experience in primary ore in Chile involves the following aspects:

- Undercut heights from 3 to $20 \mathrm{~m}$ have been generally used in the past for flat undercuts. No established single value of undercut height has been used.

- Generally, undercut heights ranging from 10 to $18 \mathrm{~m}$ have been considered in primary rock.

- The predominant choice when applying panel caving with load-haul-dumpers (LHDs), using conventional undercut, considers heights from 8 to $18 \mathrm{~m}$.

- Undercut heights ranging from 3 to $4 \mathrm{~m}$ have been used in areas with previous undercut.

- Most of the block caving cases use heights lower than $10 \mathrm{~m}$ in secondary rock.

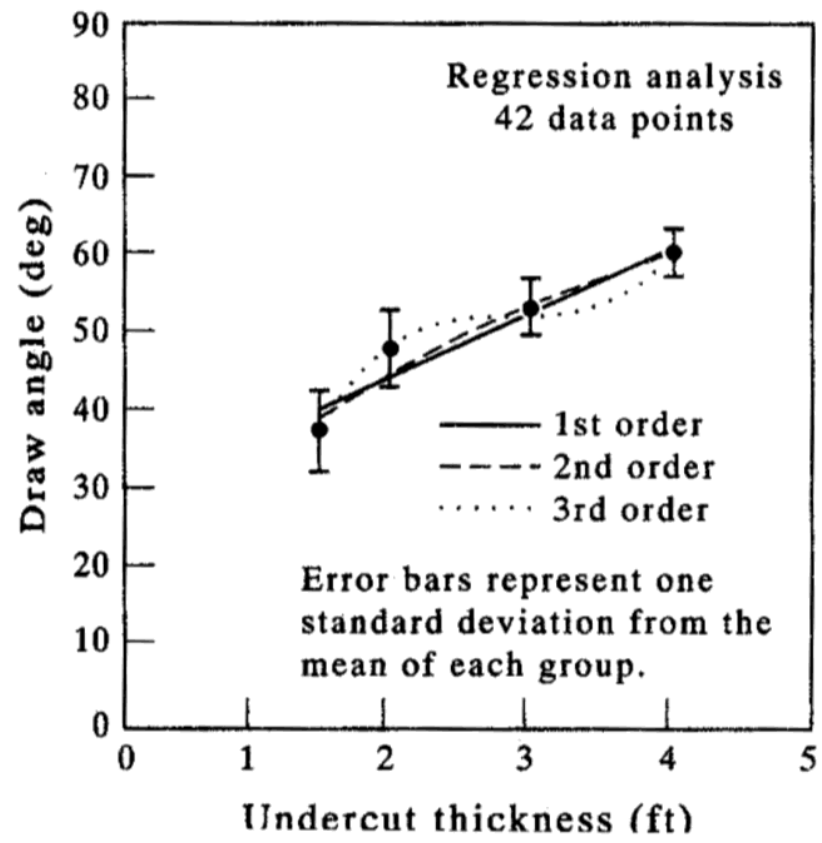

Figure 4 Relationship between undercut height (or undercut thickness) and extent of caving propagation based on physical two-dimensional models of large scale (McNearny \& Abel 1993)
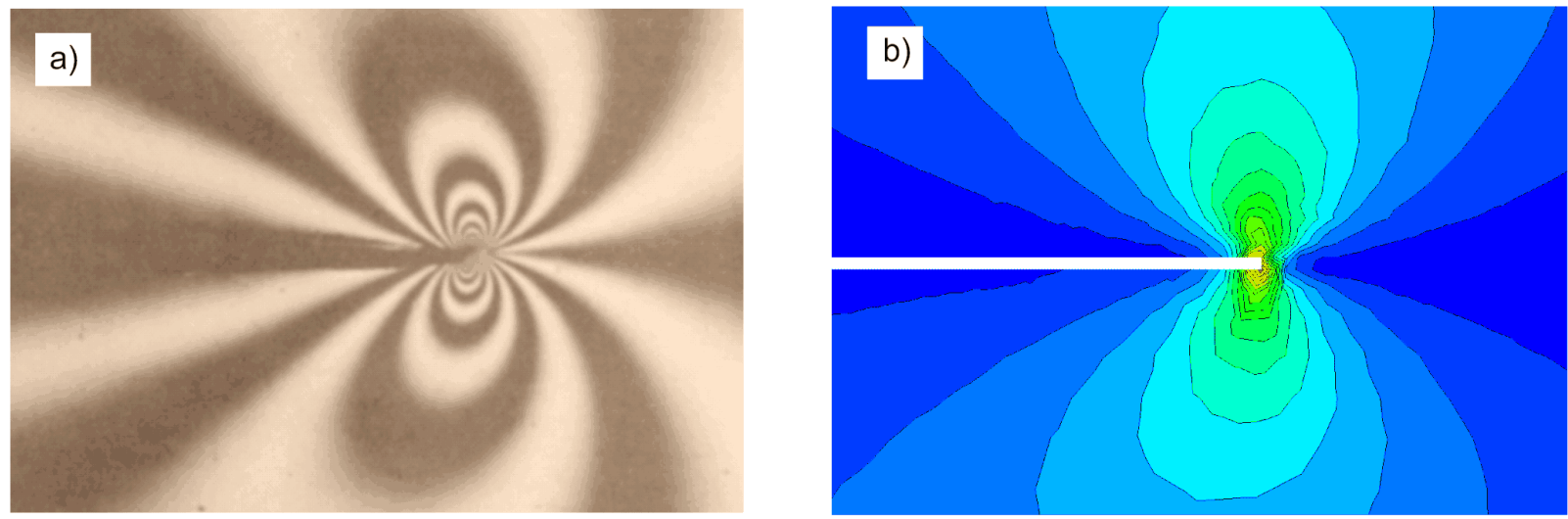

Figure 5 Stress concentrations at the abutment (or edge) of flat undercut of relatively small height; (a) Representation of isochrones corresponding to photo-elasticity models of an undercut (Camponuovo et al. 1980); and, (b) Similar representation of isochrones obtained from two-dimensional elastic numerical models (from Karzulovic 1996) 


\section{Influence of the undercut height on stress distribution}

The analysis performed by Karzulovic (1996) was replicated using the finite difference software FLAC3D (Itasca Consulting Group 2015). The objective was to look at the relationship between undercut height and magnitude of stresses occurring at the abutment of the undercut. The analysis involved a rectangular prismatic opening, representing the undercut, with a square (plan view) side length $L$ and height $H$. Several values of heights $\mathrm{H}$ were considered for the same value of length $\mathrm{L}$.

Models corresponding to $L$ values equal to $210 \mathrm{~m}$ and $\mathrm{H}$ values equal to $5,10,20$ and $40 \mathrm{~m}$ were evaluated. Figure 6 represents contours of major principal stress $\sigma_{1}$, and Figure 7 represents contours of minor principal stress $\sigma_{3}$ for each of the four cases considered. The results show that as the height of the undercut decreases, stresses tend to concentrate at the undercut front, replicating the crack effect (Karzulovic et al. 2005) with increasing magnitudes for $\sigma_{1}$ and $\sigma_{3}$ up to the level of caving (for the same undercut length).

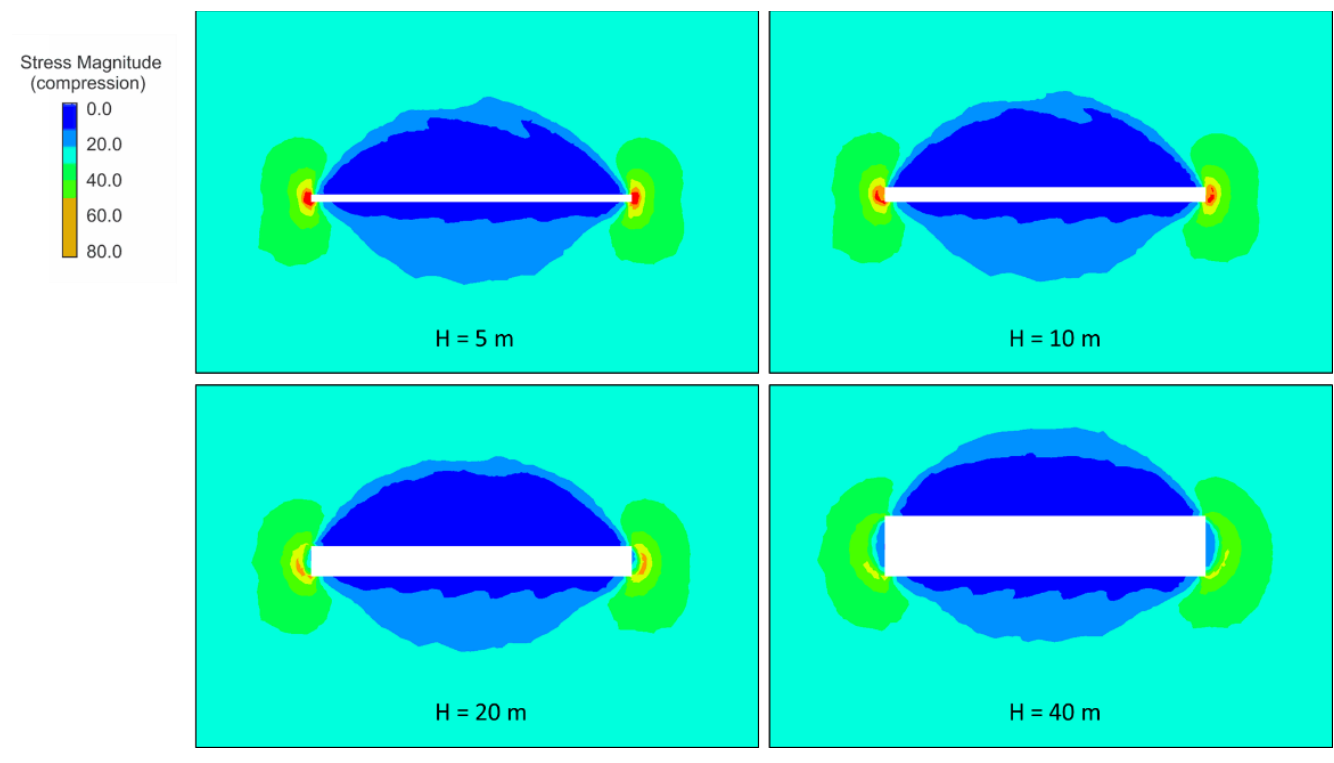

Figure 6 Contours of major principal stresses $\left(\sigma_{1}\right)$ for four flat undercuts of the same width $(120 \mathrm{~m})$ and increasing values of heights (i.e. 5, 10, 20 and $40 \mathrm{~m}$ ). The units of represented stresses are MPa

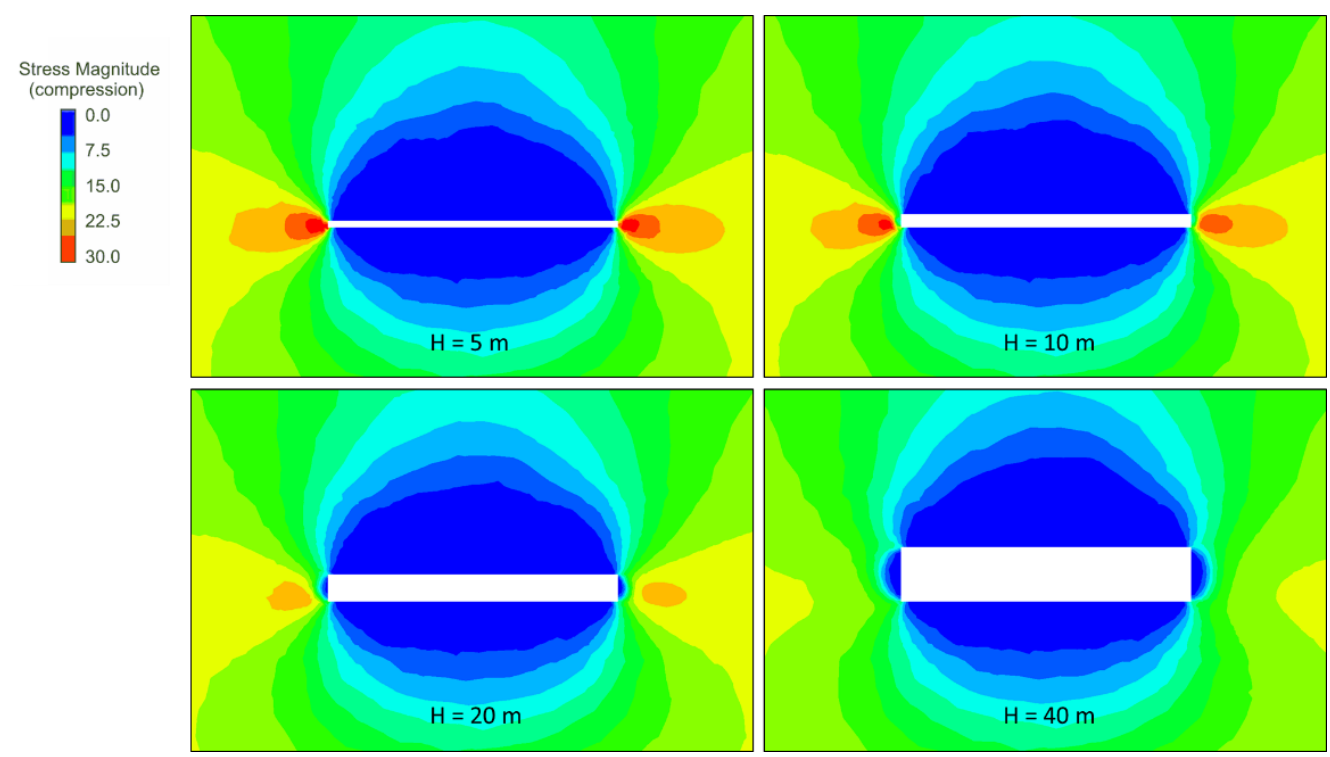

Figure 7 Contours of minor principal stresses $\left(\sigma_{3}\right)$ for four flat openings of the same width $(120 \mathrm{~m})$ and increasing values of heights (i.e. 5, 10, 20 and $40 \mathrm{~m}$ ). The units of represented stresses are MPa 
Figure 8 shows the stages of the FLAC3D model, where each stage represents a different excavation phase. In order to evaluate the behaviour of the rock mass with respect to the induced principal stresses $\left(\sigma_{1}\right.$ and $\left.\sigma_{3}\right)$, two history points were selected.

The first point on the UCL (Figure 8(a)), located at $3.5 \mathrm{~m}$ ahead of the undercut front and $2 \mathrm{~m}$ above the undercutting level, is exposed to an in situ stress state in stages 1-3 and under abutment stress state in stage 4 .

The second point, on the EXL (Figure 8(b)), located at $15 \mathrm{~m}$ ahead of the stage 4 front and $2 \mathrm{~m}$ above the extraction level floor (i.e. $16 \mathrm{~m}$ below the undercut level floor, when a crown pillar with a thickness of $18 \mathrm{~m}$ is considered between undercut and extraction levels), is exposed to an in situ stress state in stages 1-3, under abutment stress state in stage 4 and a relaxation state in stages 5-7.

(a) History point at UCL

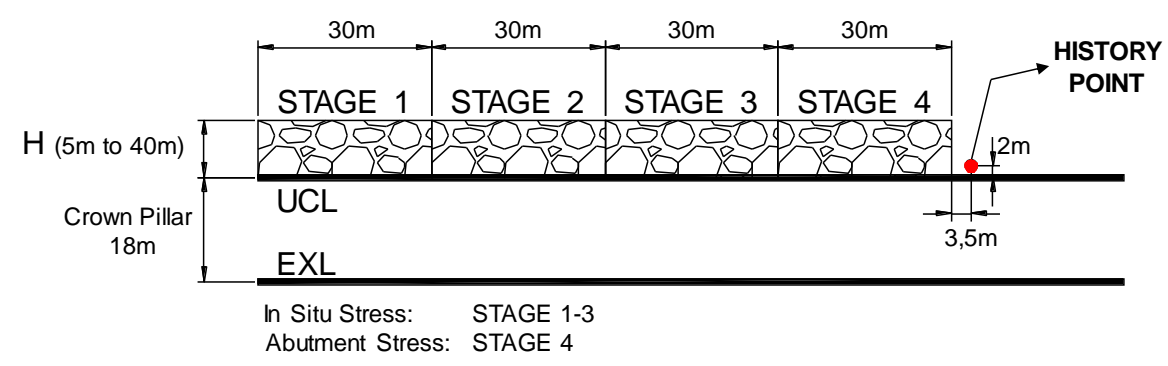

(b) History point at EXL

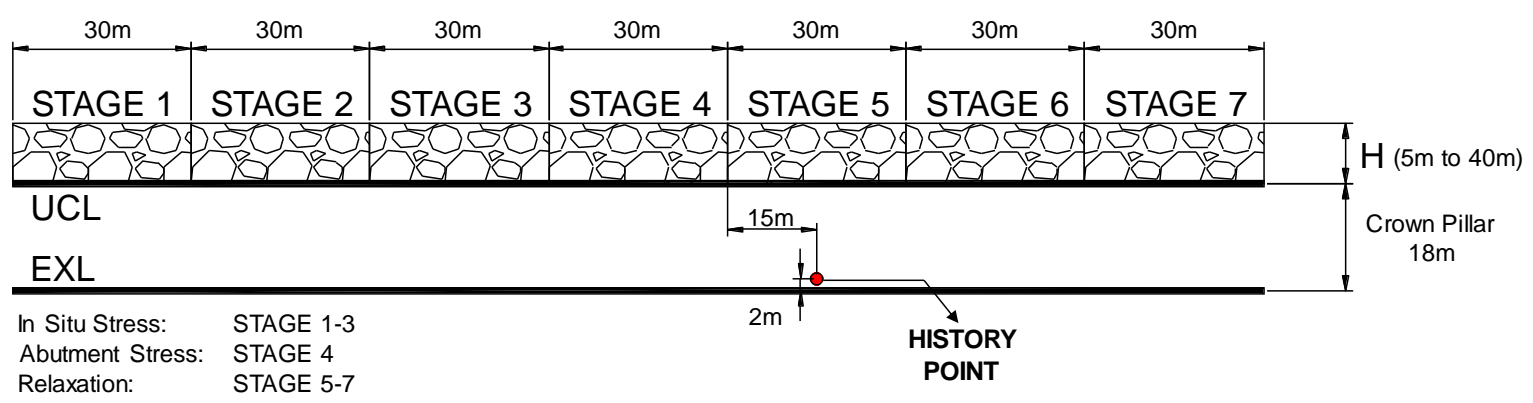

Figure 8 Schematic cross-section of the stages considered in the FLAC3D model and the respective evaluated history points; (a) History point at UCL; and, (b) History point at EXL

Figure 9 shows the traces of induced principal stresses (i.e. stress paths) for the two history points in the rock mass under evaluation.

The stress paths of the history point located on the UCL (Figure 9(a)) are compared for each H value $(5,10$, 20 and $40 \mathrm{~m}$ ). It is observed that even though smaller undercut heights ( 5 and $10 \mathrm{~m}$ ) concentrate higher stresses $\sigma_{1}$, they also concentrate higher (confining) stresses $\sigma_{3}$. Therefore, history points are moved to major confinements under the failure envelope inducing a more stable condition, reducing the potential of rock mass breaking or unravelling.

On the other hand, for larger undercut heights (20 and $40 \mathrm{~m}$ ), the major principal stress $\sigma_{1}$ is slightly reduced and the confinement stress $\sigma_{3}$ is prominently reduced, which makes the control point move to lower confinements (i.e. relaxation takes place), remaining closer to the failure envelope, and thus inducing an unstable condition that promotes the caving process.

Considering now the stress path of the history point located on the extraction level (Figure 9(b)), it is observed that for all the heights, the behaviour is similar. However, for smaller values of undercut heights ( 5 and $10 \mathrm{~m}$ ), there is an increase of the major principal stress $\sigma_{1}$ and a slight decrease of the confinement stresses $\sigma_{3}$, for the conditions of abutment stress and relaxation, with respect to the cases of larger values of undercut heights (20 and $40 \mathrm{~m}$ ). 


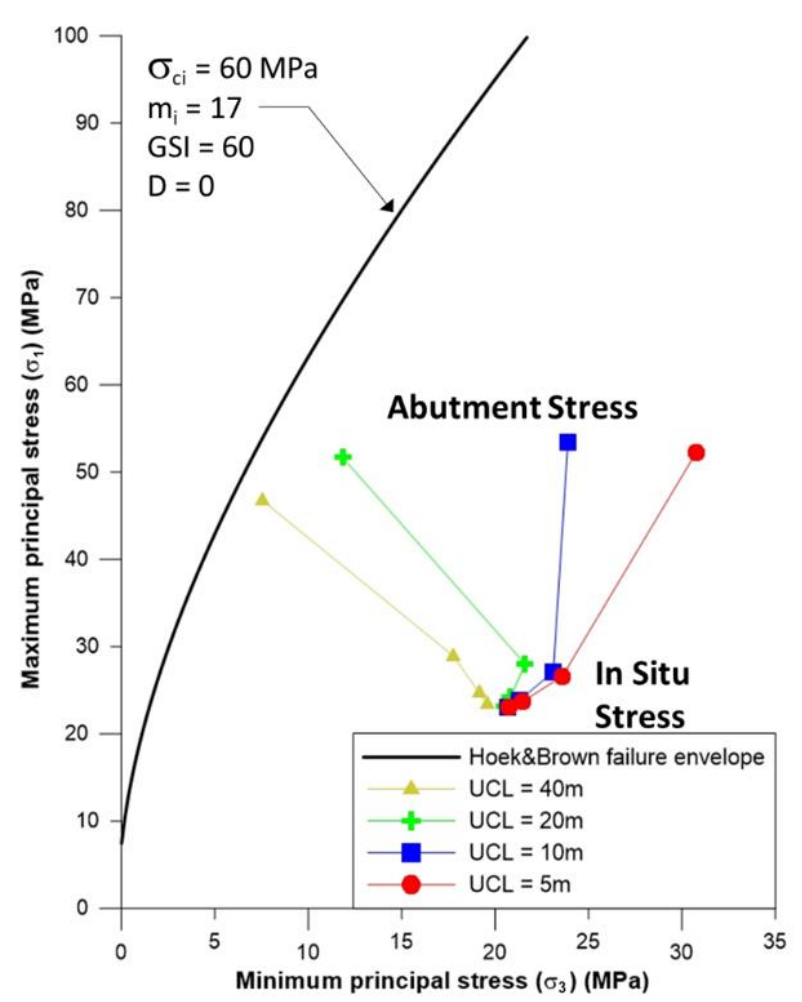

(a)

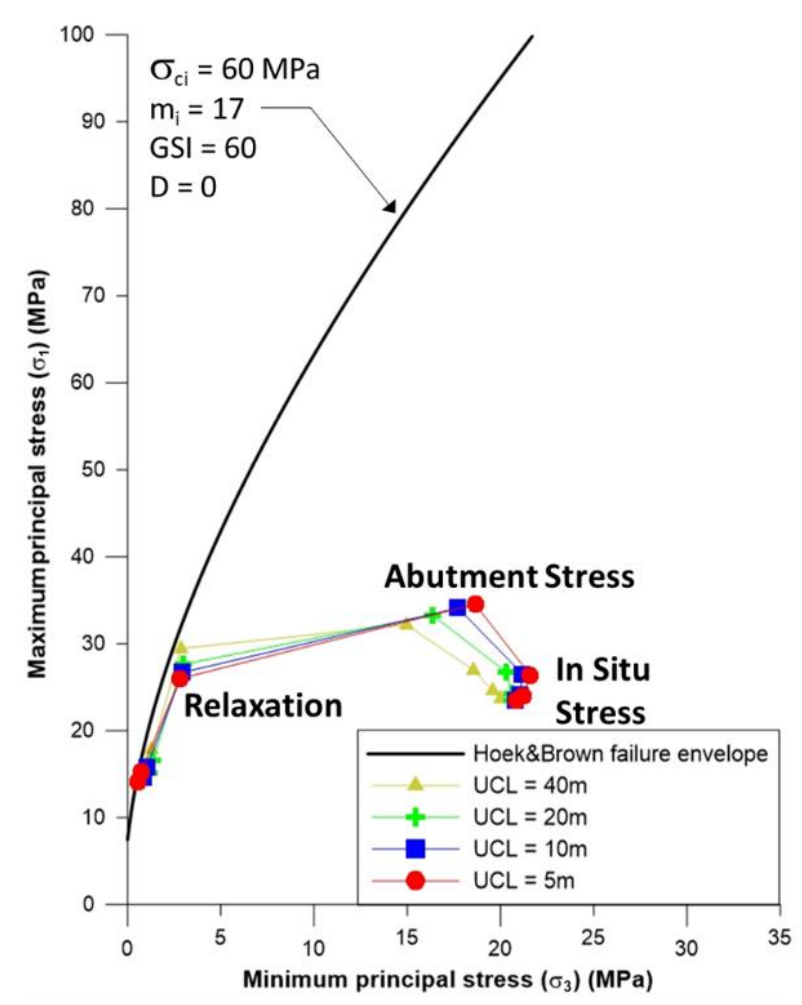

(b)

Figure 9 Traces of induced principal stresses (i.e. stress paths) for two points in the rock mass located at (a) The undercutting level; and, (b) The extraction level, for different heights of the undercutting opening

\section{$4 \quad$ Stability analysis of pillars at the extraction level}

To further understand the effect of the undercut height on the stresses generated in the rock mass, detailed three-dimensional models considering production drifts, undercut drifts, mining process and different surfaces of broken material simulating the caving propagation were built.

Figure 10 shows an isometric view of the model where the modelled sequence can be described as follows:

1. Main drifts (production drifts, drawpoint drifts and undercut drifts) are excavated in the extraction level and undercut level.

2. Mining process simulation, which consists of a sequential excavation of drawbells line-by-line in the direction of the advance of the undercut, followed by excavation of the undercutting stages (stages 1,2 , etc.), which is done until the panel is complete.

The undercutting stages have approximately $30 \mathrm{~m}$ of length, and two to three lines of drawbells are left ahead of the undercut front. With regard to the numerical models presented in this section, it should be noted that the models do not simulate the actual propagation of caving, but rather account for a front of 'broken' material that advances in time, as dictated by the given sequencing of excavation. 


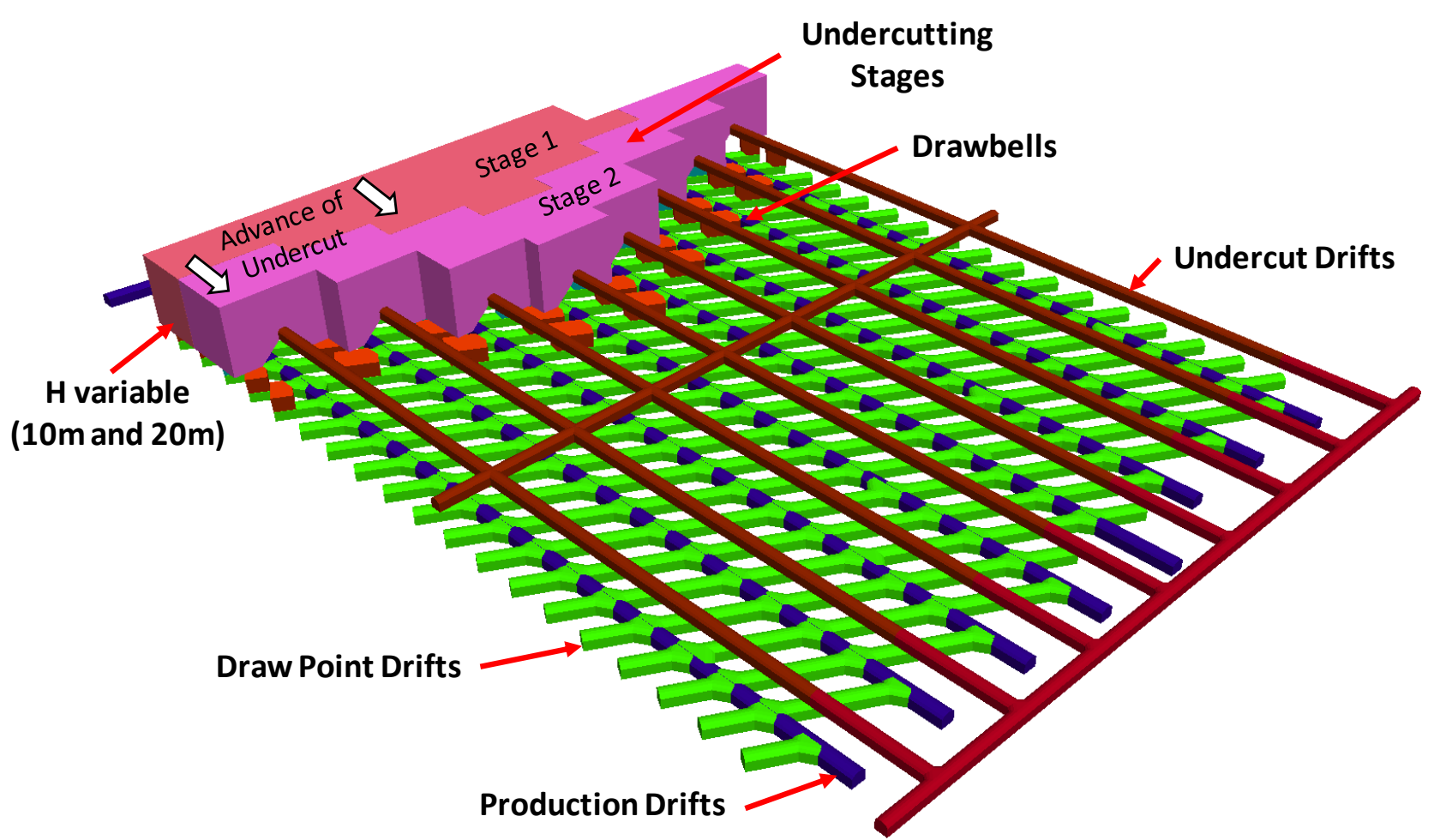

Figure 10 Isometric view of a three-dimensional numerical model used to analyse the stress concentration in the pillars of a caving operation

Table 1 lists geometrical and geotechnical parameters used in the model. As indicated in the table, two different undercut heights equal to 10 and $20 \mathrm{~m}$ were considered.

Table 1 Geometrical parameters used in the three-dimensional model represented in Figure 10

\begin{tabular}{|c|c|c|c|}
\hline \multicolumn{3}{|c|}{ Parameters } & \multirow{2}{*}{$\begin{array}{l}\text { Values } \\
32\end{array}$} \\
\hline \multirow{6}{*}{$\stackrel{\vec{J}}{د}$} & \multirow{3}{*}{$\stackrel{n}{\stackrel{ \pm}{ \pm}}$} & Spacing $(m)$ & \\
\hline & & Height (m) & 4.0 \\
\hline & & Width (m) & 4.0 \\
\hline & \multicolumn{2}{|c|}{ Undercut height (m) } & 10 and 20 \\
\hline & \multicolumn{2}{|c|}{ Undercutting variant } & Conventional (post) \\
\hline & \multicolumn{2}{|c|}{ Undercutting type } & Flat undercut \\
\hline \multirow{5}{*}{ 오 } & \multirow{5}{*}{ 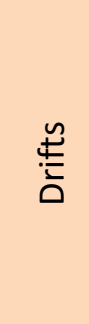 } & Crown pillar (m) & 18 \\
\hline & & LHD layout type & El Teniente \\
\hline & & Spacing $(m)$ & 32 \\
\hline & & Height (m) & 5.2 \\
\hline & & Width (m) & 4.85 \\
\hline \multicolumn{2}{|c|}{ Drawpoints } & Spacing $(m)$ & 15 \\
\hline
\end{tabular}

For the purpose of facilitating the interpreting results, in the numerical model each pillar is considered to be an independent volume with a unique designator. Also, each pillar is subdivided into a 'top of the pillar' (TP) and 'bottom of the pillar' (BP), with the limiting horizontal boundary located at the top height of the production drifts (Figure 11). Considering that, the BP (between extraction level floor and the mentioned 
horizontal boundary) shows a higher excavation rate in the mining layout. This BP is considered to be the region where major damage takes place. Because of this, the BP was the focus of the analysis.

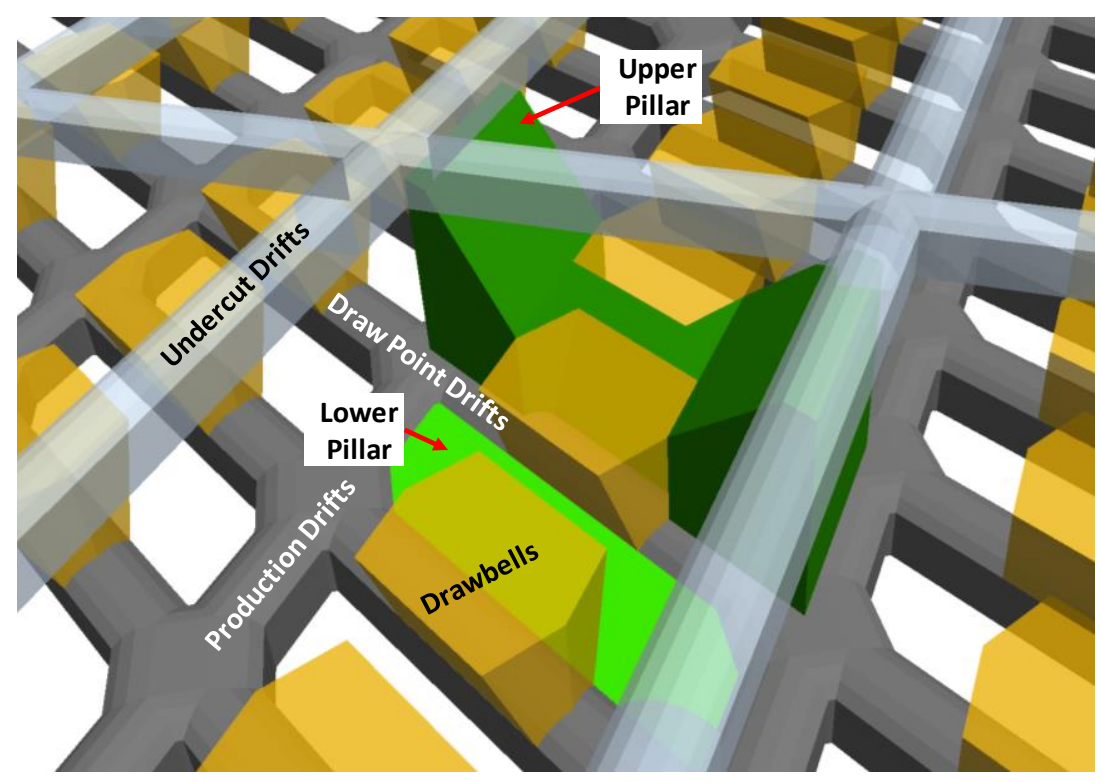

Figure 11 Close-up view of a three-dimensional numerical model of a generic pillar at the extraction level, shown in green

The calculation of the Factor of Safety (FS) for the rock mass was performed according to the methodology proposed by Hoek and Brown (1980), defined as the ratio between capacity and demand (or available shear strength and acting shear stress). The computation of FS was implemented through a FISH programming scheme (Figure 12).

$$
F S=\frac{A}{B}=\frac{\sigma_{1 \max }}{\sigma_{1}}
$$

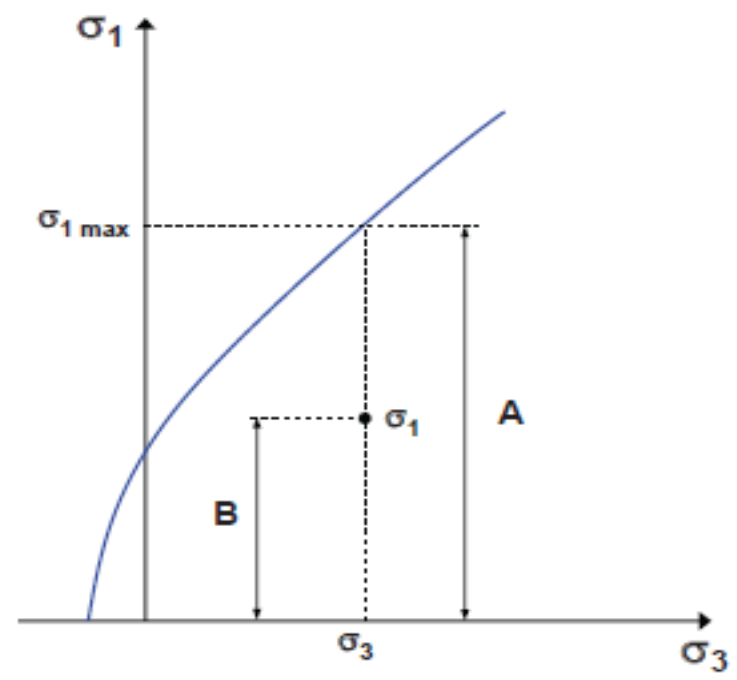

Figure 12 Definition of FS used in the analysis

The FS was computed for each pillar in the three-dimensional model. Factors of safety for the pillars were evaluated in each modelling stage of the mining process.

In order to define the shear strength (or shear failure stress) of an elasto-plastic material, it is necessary to define a failure envelope in the space of principal stresses $\sigma_{1}$ and $\sigma_{3}$. This envelope is the curve that limits the stress combinations that the material is able to withstand. For a principal stress state above the failure envelope, the material is not able to withstand the stress state. This case corresponds to FS $<1$ when 
considering an elasto-plastic material model for the rock mass, as is the case of the three-dimensional model in this analysis. This condition is never reached, as the material starts yielding plastically when $\mathrm{FS}=1$. Similarly, for a principal stress state below the failure envelope, the material withstands the stress state; this case corresponds to FS $>1$.

To interpret the degree of failure of the pillars, three intervals where considered for the Factor of Safety; $\mathrm{FS} \leq 1,1<\mathrm{FS} \leq 1.5$ and FS $>1.5$. Considering that in the FLAC3D model, each pillar is comprised of many (mesh) elements three-dimensionally distributed, the FS was computed for each element (zones) and regions. Figure 13 shows the three-dimensional distribution of the computed FS in the three intervals mentioned above.

a) FS $\leq 1$

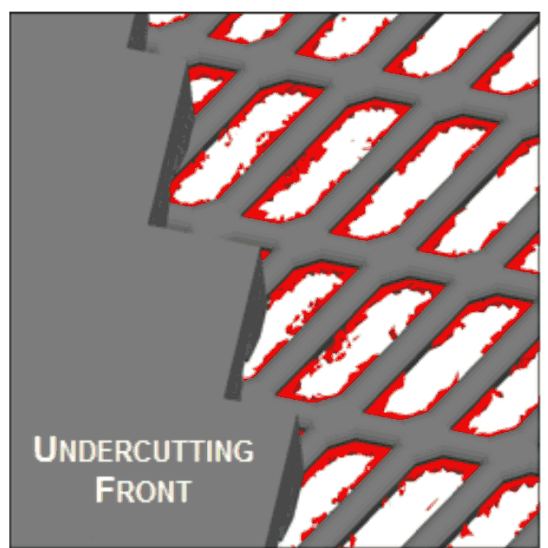

b) $1<\mathrm{FS} \leq 1.5$

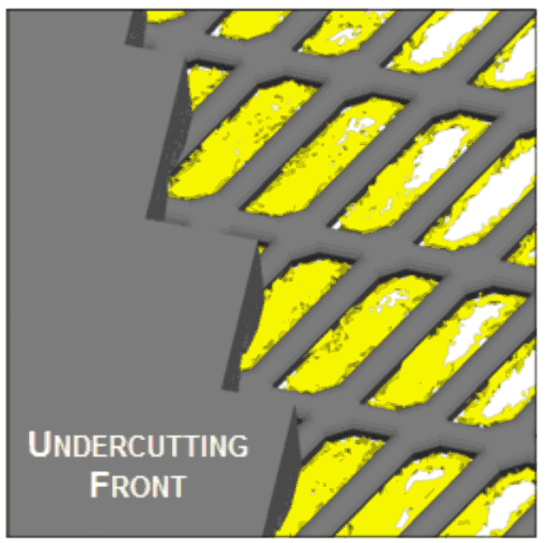

c) FS $>1.5$

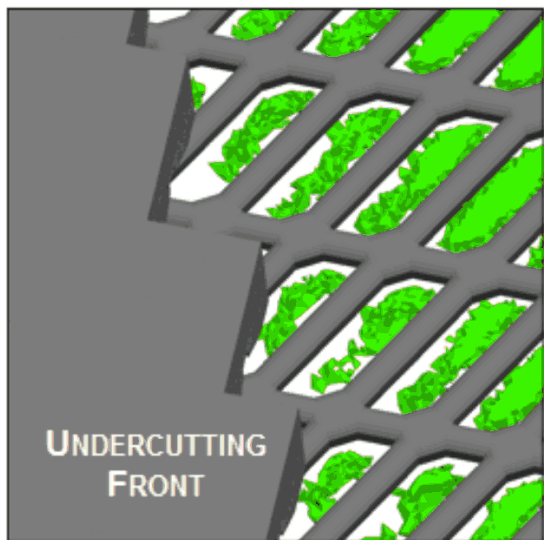

Figure 13 Distribution of the computed factors of safety in pillars near the undercutting front (abutment stress zone). The damage, as represented, is quantified in terms of a Factor of Safety (FS $<1$ )

It should be emphasised that this computation was done for the different stages of the simulation of the mining progression. Also, considering that the sum of volumes for all elements gives the total volume of the pillar, the percentage of pillar volume falling into each of three intervals mentioned above was also computed (Figure 14).

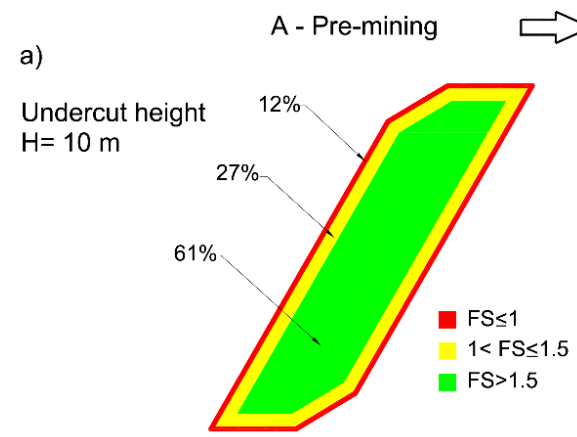

B - Abutment stress

$\Rightarrow$

C- Relaxation

b)
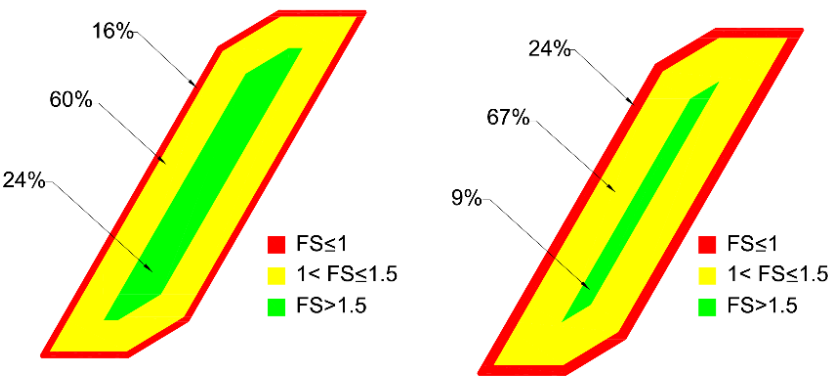

Undercut height $\mathrm{H}=20 \mathrm{~m}$
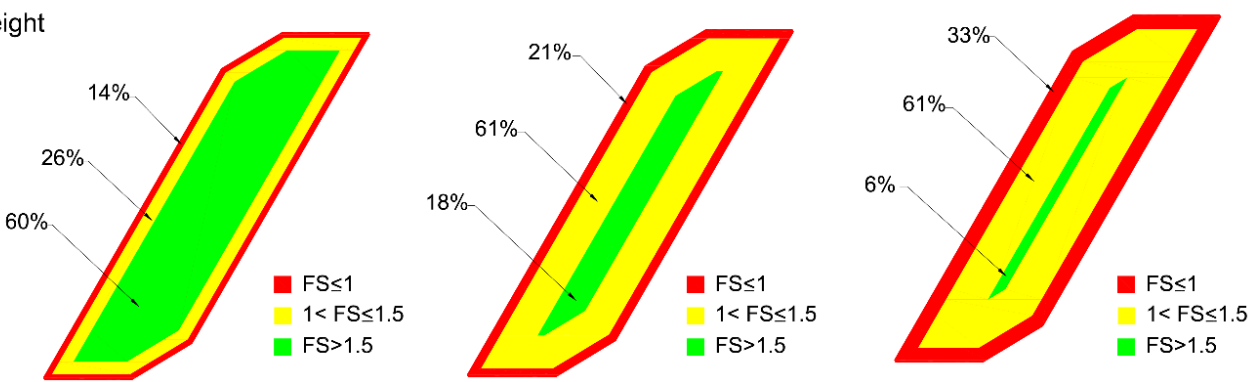

Figure 14 Pillar sketch showing the FS distribution at three different stages of the mining operation (indicated as A, B and C) for two different heights of undercutting, namely (a) $10 \mathrm{~m}$; and, (b) $20 \mathrm{~m}$ 
Various criteria exist to define acceptability of pillar stability in the practice of mining. The ones frequently used are based on acceptable values for the FS and Probability of Failure (PF). In the analysis presented in this paper, only the FS was considered as a measure of stability of the pillars, being understood that as the pillars experience the effects of mining (particularly as the caving front passes over a pillar), the pillar will be temporarily overstressed, and subsequently will be unstressed (or relaxed). From the analysis of the three-dimensional model, it was indeed observed that stress concentrations were generated in pillars during the undercut stage, and that this induced failure on the external surfaces (i.e. walls) of the pillar only, not affecting the core or internal volume of the pillar, which remained elastic (Figure 13).

To summarise, the analysis of results obtained from the three-dimensional model indicate the following (Figure 14):

- Pre-mining: The percentages of the safety factor intervals are very similar for both 10 and $20 \mathrm{~m}$ undercut heights. A high percentage is observed for a FS $>1.5$ over $60 \%$. A low percentage is observed for a FS $<1.0$ around a $12 \%$, mainly caused by the construction of production drifts, undercut drifts and drawbells.

- Abutment stress: It is in this zone that the main differences in undercutting height are observed. In the interval FS $<1.0$, a difference of $5 \%$ is observed between an undercut height of $10 \mathrm{~m}$ $(\mathrm{FS}<1.0=16 \%)$ and an undercut height of $20 \mathrm{~m}$ (FS $<1.0=21 \%)$. In the interval $\mathrm{FS}>1.5$, a difference of $6 \%$ is observed between an undercut height of $10 \mathrm{~m}(\mathrm{FS}>1.5=24 \%)$ and an undercut height of $20 \mathrm{~m}$ ( $\mathrm{FS}>1.5=18 \%)$. The interval $1<\mathrm{FS} \leq 1.5$ is similar in both cases.

- Relaxation: In the interval FS $<1.0$ a difference of $9 \%$ is observed between an undercut height of $10 \mathrm{~m}(\mathrm{FS}<1.0=24 \%)$ and an undercut height of $20 \mathrm{~m}(\mathrm{FS}<1.0=33 \%)$. The interval $1<\mathrm{FS} \leq 1.5$ shows a difference of $6 \%$ between an undercut height of $10 \mathrm{~m}(1.0<\mathrm{FS} \leq 1.5=67 \%)$ and an undercut height of $20 \mathrm{~m}(1.0<\mathrm{FS} \leq 1.5=61 \%)$. In the interval FS $>1.5$ a difference of $3 \%$ is observed between an undercut height of $10 \mathrm{~m}$ ( $F S>1.5=9 \%)$ and an undercut height of $20 \mathrm{~m}$ ( $F S>1.5=6 \%)$.

In the three zones of analysis, pre-mining, abutment stress and relaxation, the results of the three-dimensional model show better performance of the pillars for a lower undercut height $(10 \mathrm{~m})$ compared to a higher undercut height $(20 \mathrm{~m})$.

\section{Conclusion}

The results obtained from numerical models in this study indicate that as the undercut height decreases, stresses tend to concentrate at the undercut front, producing the crack effect discussed in Karzulovic et al. (2005), and increasing the magnitude of the major principal stress $\sigma_{1}$ at the floor of the undercutting level (for the same caving front distance). These results indicate that for small caving heights, there is an increase in concentration of stresses (at the floor of the undercutting level) compared with the case of large caving heights. The results also suggest that at the extraction level, the behaviour for stresses is better for a smaller undercutting height.

Based on the experience of block caving for primary ore in mines in Chile, and based on the results obtained from the numerical analyses presented in this study, undercut heights larger than $10 \mathrm{~m}$ facilitate cave propagation and reduce generation of remnant pillars. Nevertheless, undercut heights larger than $10 \mathrm{~m}$ require wider pillars and more robust rock support for pillars and drifts. On the other hand, undercut heights smaller than $10 \mathrm{~m}$ could affect the cave propagation process, increasing the probability of occurrence of remnant pillars. Undercut heights smaller than $10 \mathrm{~m}$ could increase the stability of pillars at the extraction level, especially if advance or pre-undercutting is used. 
From a practical point of view, prior to reaching the hydraulic radius, the cavity of larger undercutting heights takes the geometry of the blasting pattern so broken material creates a bed between the undercutting floor and the cave back. This condition helps to manage the initial cave geometry, which is when the material is detached from a flat roof as potential big blocks. Having this broken material bed minimises hang-ups at the extraction point, improving the regularity of cave propagation and, therefore, the distribution of the abutment stress.

\section{Acknowledgement}

The work presented in this paper was motivated by the seminal work on caving mechanics done by the late Dr Antonio Karzulovic in Chile. His contribution to the understanding of the mechanics of caving operations had a significant impact, not only in mining operations in Chile, but also in mining operations throughout the world.

\section{References}

Camponuovo, G, Freddi, A \& Borsetto, M 1980, Hydraulic Fracturing of Hot Dry Rocks. Tri-dimensional Studies of Crack Propagation and Interaction by Photoelastic Methods, report no. 136, Institute of Experimental Models and Structures, Bergamo.

Dai, C, Mühlhaus, H, Meek, J \& Duncan Fama, M 1996, 'Modeling of blocky rock masses using the Cosserat method', International Journal of Rock Mechanics and Mining Sciences \& Geomechanics Abstracts, vol. 33, no. 4, pp. 425-432.

Flores, G \& Karzulovic, A 2002, Benchmarking Report, prepared for the International Caving Study Stage 2 (ICS-II), Julius Kruttschnitt Mineral Research Centre and Itasca Consulting Group, Inc., Brisbane.

Hoek, E \& Brown, ET 1980, Underground Excavations in Rock, The Institute of Mining and Metallurgy, London.

Itasca Consulting Group 2015, FLAC3D, computer software, version 5.0, Itasca Consulting Group, Minneapolis.

Karzulovic, A 1996, Rock Mechanics Notes Related to Esmeralda Sector, El Teniente Division, Codelco, Santiago.

Karzulovic, A, Gaete, S, Pizarro, E, Rubio, J \& Seguel, J 2005, Effect of the Undercutting Geometry in the UCL Pillars, Esmeralda Sector, El Teniente Division, Codelco, Santiago.

McNearny, R \& Abel, J 1993, 'Large-scale two-dimensional caving model tests', International Journal of Rock Mechanics and Mining Sciences \& Geomechanics Abstracts, vol. 30, no. 2, pp. 93-109.

Shen, B \& Barton, N 1997, 'The disturbed zone around tunnels in jointed rock masses', International Journal of Rock Mechanics and Mining Sciences \& Geomechanics Abstracts, vol. 34, no. 1, pp. 117-125. 